\title{
COMUNICAÇÃO E TERCEIRO SETOR: um estudo no município de Guarapuava/Paraná
}

\author{
Communication and third sector: a study in Guarapuava, Paraná
}

\author{
Márcio David Macedo da Silva ${ }^{a}$, Queila Regina Souza ${ }^{b}$ \\ a Graduado em Publicidade e Propaganda pela Universidade Federal do Pará, com especialização em Comunicação Empresarial \\ pela Pontifícia Universidade Católica do Paraná. Guarapuava, PR - Brasil, e-mail: mdmacedos@yahoo.com.br \\ b Doutoranda em administração (UFPR), Mestre em Administração (PUCPR), Especialista em Comunicação, Docente dos cursos \\ Graduação e Pós-Graduação em Comunicação Social PUCPR. Curitiba, PR - Brasil, e-mail: queila.s@pucpr.br
}

\section{Resumo}

Apesar de muito celebrado como uma das novidades em termos de alternativa na formulação de políticas públicas e na prestação de serviços de interesse social, o "Terceiro Setor" ainda é relativamente pouco pesquisado pela academia brasileira. Desta forma, os resultados da pesquisa de campo aqui apresentada, realizada com entidades atuantes no terceiro setor em Guarapuava/ PR, procura identificar quais ferramentas de comunicação as entidades utilizam para falar com seus diversos públicos. Além disso, apresenta alguns conceitos de comunicação aplicados ao terceiro setor tais como processos e estratégias comunicacionais. A seleção de entidades pesquisadas foi feita junto à Secretaria de Promoção Social do município e do Grupo de Voluntários Lobo Solidário. A partir da análise dos dados obtidos, percebe-se que a utilização sistemática de ferramentas de comunicação não é uma prática disseminada entre os vários tipos de organizações do Terceiro Setor em Guarapuava. Nenhuma das organizações pesquisadas apresentou características que caracterizem o uso eficiente e profissional da comunicação. Concluiu-se que há dispersão de esforços na comunicação, além de dificuldade generalizada de identificação e acesso ao públicos-alvo.

Palavras-chave: Terceiro setor; Comunicação; Marketing social.

\begin{abstract}
Despite of being celebrate as an innovation as an alternative to public policies formulation and social services promotion, the so called Third Sector is not very frequently studied by Brazilian academy. This research was made to contribute to this area of knowledge and was performed at organizations of third sector Guarapuava, Paraná. The objective was to identify communication tools used to keep the relationship with their stakeholders. Besides, presents some communication
\end{abstract}


theory concepts applied to third sector organizations such as processes and strategies. The organizations were selected from lists provided by Social Promotion Secretary of Guarapuava and Lobo Solidário Volunteer Group. It was concluded that systematic use of communication tools is not a common practice between the organizations studied. Besides, there is not efficiency and professionalism in the use of communication as strategy. In general, it was found difficulty of identification and access to stakeholders.

Keywords: Third sector; Communication; Social marketing.

\section{INTRODUÇÃO}

Cada vez mais as organizações do Terceiro Setor, aqui entendido como setor à parte do empresarial e do governamental, reconhecem a importância da utilização de estratégias eficientes de comunicação como forma de alcançarem seus objetivos organizacionais. Portanto, considera-se como pressuposto básico que a compreensão do atual quadro de utilização das ferramentas de comunicação por parte dessas organizações sem fins econômicos é um passo importante no sentido de aprimorar sua compreensão e utilização mais ampla e eficiente.

Pressupõe-se, ainda, com base em estudos anteriores, que a maior parte dos dirigentes de entidades do Terceiro Setor brasileiras não possuem conhecimentos específicos nas áreas de marketing e comunicação. Portanto, na maior parte das vezes, estas entidades enfrentam problemas de posicionamento junto aos seus públicos estratégicos. Ao mesmo tempo, muitas dificuldades poderiam ser minimizadas, ou até mesmo eliminadas, se as entidades utilizassem as ferramentas de comunicação e marketing adequadas às suas necessidades de forma profissional e sistematizada.

$O$ desafio da sustentabilidade organizacional, portanto, envolve não apenas a adequada captação e utilização de recursos financeiros, mas também o desenvolvimento contínuo dos recursos humanos que compõem a organização, o melhoramento contínuo dos serviços, a adequação das atividades às necessidades das comunidades e, principalmente, um processo de comunicação eficiente, processual, profissional e transparente junto a seus diversos públicos.

De acordo com Grunig (1992, p. 57), no contexto da comunicação estratégica organizacional, entidades do Terceiro Setor tem à sua disposição diversos meios de comunicação que lhes permitem relacionar-se com seus públicos, entre esses: contatos pessoais, cartas, telefonemas, e-mails ou websites, além de materiais institucionais como folhetos, brochuras, folders, boletins ou jornais. $\mathrm{O}$ cuidado na elaboração desses materiais é muito importante porque, não raro, são esses os veículos que transmitem a imagem da organização para os diferentes públicos que já possuem ou podem vir a ter algum interesse na organização (seus stakeholders).

Como forma de contribuição para o aumento do conhecimento a respeito destes temas, este trabalho procurou avaliar elementos constitutivos da estratégia de entidades do Terceiro Setor em Guarapuava/PR, especificamente em termos da utilização das ferramentas de comunicação. $O$ objetivo geral foi analisar, ainda que parcialmente, o perfil das atividades de comunicação desenvolvidas pelas organizações pesquisadas e os resultados obtidos em relação a um conjunto de públicos-alvo com os quais mantêm contatos.

A técnica de coleta de dados seguiu uma amostragem não-probabilística na obtenção dos dados. Os dados secundários foram obtidos por meio de levantamento bibliográfico, monografias, textos e websites, complementados por informações obtidas a partir de dados primários. A obtenção dos dados primários ocorreu por meio de entrevistas individuais, utilizando-se questionários estruturados, aplicados junto aos diretores e presidentes das entidades filantrópicas, entre os dias $1^{\circ}$ e 20 de agosto de 2004 , sendo que cada entrevista teve duração média de 45 minutos. Do total de 27 entidades identificadas por meio de cadastro disponibilizado por instituições do município, foi retirada uma amostra de 10 entidades, representando $37 \%$ das organizações.

\section{O terceiro setor e os desafios para o futuro}

O termo Terceiro Setor surgiu no início dos anos 70, nos EUA, para identificar um setor da sociedade no qual atuam organizações sem fins lucrativos, voltadas para a produção ou distribuição de bens e serviços de interesse público. 
Considere-se o Estado em toda sua amplitude como uma instituição caracterizada por meios públicos para fins públicos e as empresas como meios privados para fins privados. Respectivamente, suas instituições integrantes são usualmente denominadas de instância pública (Primeiro Setor) e iniciativa privada (Segundo Setor). Além destes setores tradicionais, portanto, considerem-se também duas exceções: meios públicos para fins privados (corrupção) e meios privados para fins públicos. Ao último denomina-se Terceiro Setor, do qual fazem parte, em nível mundial, organizações não governamentais, institutos e fundações (de iniciativa empresarial ou comunitária), entidades de classe e beneficentes, associações profissionais, movimentos sociais os mais variados, enfim, uma ampla gama de entidades cujo propósito essencial é atender a uma determinada necessidade social.

No Brasil, a atual legislação prevê a existência de dois formatos para organizações sem fins econômicos: associações e fundações. É importante frisar que a diferença fundamental entre as organizações do Terceiro Setor e outros movimentos sociais é a existência de uma estrutura formal permanente. Entenda-se estrutura formal permanente, neste caso, uma estrutura física ou social persistente no tempo e que proporcione suporte aos objetivos da organização. Além disso, estas organizações precisam comprovar a prestação de serviços coletivos de interesse da sociedade ou de grupos da sociedade e devem ter estatuto, conselho diretor e conselho fiscal. São denominadas genericamente de ONGs (organizações nãogovernamentais) as organizações vinculadas a determinados segmentos sociais ou quando responsáveis pela "advocacia” de causas e direitos. Em termos de gestão, as fundações são mais sofisticadas, possuem mais recursos, além de uma estrutura operacional mais profissional, provavelmente por estarem vinculadas diretamente a grandes empresas (COELHO, 2000).

Portanto, para efeitos deste trabalho, consideraram-se como integrantes do Terceiro Setor as entidades que estão cadastradas na Secretaria de Promoção Social do Município de Guarapuava e também no Centro de Voluntariado Lobo Solidário e que cumprem, no mínimo, o exposto no parágrafo $1^{\circ}$ do artigo $1^{\circ}$ da Lei $9.790 / 99$, também conhecida como Marco Legal do Terceiro Setor:
Para os efeitos desta Lei, considera-se sem fins lucrativos a pessoa jurídica de direito privado que não distribui, entre os seus sócios ou associados, conselheiros, diretores, empregados ou doadores, eventuais excedentes operacionais, brutos ou líquidos, dividendos, bonificações, participações ou parcelas do seu patrimônio, auferidos mediante o exercício de suas atividades, e que os aplica integralmente na consecução do respectivo objeto social. (DIÁRIO OFICIAL DA UNIÂO, LEI N. 9.790, DE 23 DE MARÇO DE 1999, $₫ 1^{\circ}$ ).

Ainda que a expressão "sem fins lucrativos" esteja muito presente nas organizações do Terceiro Setor, isto não significa que estas instituições não busquem lucro, pois necessitam de superávit financeiro para repor o capital e financiar novas atividades. Portanto, mais recentemente, a designação tem sido substituída pela expressão "sem fins econômicos".

O Terceiro Setor no Brasil já acumula um certo capital de recursos, experiências e conhecimentos sobre formas inovadoras de enfrentamento de questões sociais que qualificam as entidades de maior expressão como interlocutoras e parceiras das políticas governamentais. Em sua relação com os outros setores, as organizações sem fins econômicos começam a atrair parcerias com empresas privadas e com o governo na realização de empreendimentos sociais. Aos poucos, desenvolvese a consciência pela necessidade de profissionalização tanto das atividades-meio destas organizações (administração) quanto das atividadesfim (a ação social propriamente realizada).

Há hoje no Brasil mais de 320 mil OSC's (Organizações da Sociedade Civil), empregando em torno de 2,0 milhões de pessoas, segundo dados da RITS - Rede de Informações do Terceiro Setor - e excetuando-se sindicatos e entidades do Sistema S: Senai, Sesc, Sesi, Sebrae. Acredita-se que o Terceiro Setor tem hoje potencial para absorver profissionais das mais variadas áreas: administração de empresas, finanças, marketing, recursos humanos, consultoria, captação de recursos, biologia, assistência jurídica, engenharia, pesquisa científica, além de todo um vastíssimo leque de funções técnicas.

Mais especificamente no campo das comunicações, é possível verificar que há espaço para a presença do profissional de comunicação dentro do cenário da atividade social. Dentro do quadro crescente de profissionalização e fortaleci- 
mento institucional do Terceiro Setor, a RITS (2004) considera, ainda, que as OSCs mais dinâmicas estão investindo na qualificação de suas próprias informações "sobre os fins (o que fazem, para quem, com que resultados) e sobre os meios (como fazem, com que recursos físicos, humanos e financeiros). Consciente de suas próprias limitações e portunidades, a OSC é capaz de se comunicar melhor com seus público-alvo: defini-lo com clareza e divulgar suas mensagens. Sabendo de si e de seu público, é capaz de informar melhor os potenciais financiadores: os próprios beneficiários, empresas, fundações ou órgãos de governo".

\section{COMUNICAÇÃO NO TERCEIRO SETOR}

\section{A comunicação como processo}

Everett Rogers, teórico da Comunicação, definiu a comunicação como "processo no qual os participantes criam e compartilham a informação para alcançar uma compreensão mútua" (apud MATTELART; MATTELART, 1999, p. 158). Muito poderia ser descrito a respeito da importância da comunicação para o Terceiro Setor, e o início da discussão poderia partir do argumento de que a comunicação prescreve comportamentos e atitudes por meio da sugestão de códigos simbólicos, revelando seu caráter voltado ao individual. A rigor, é possível argumentar que "a comunicação caminha na direção da inclusão, da integração" (MORAN, 1998, p. 10), dois prismas são considerados fundamentais para o trabalho desenvolvido no Terceiro Setor.

De acordo com Rego (1986, p. 17), “a comunicação que, enquanto processo, transfere simbolicamente idéias entre interlocutores, é capaz de, pelo simples fato de existir, gerar influências." Esta abordagem já serve para justificar o fato de que o exercício da comunicação é fundamental para as organizações da área social, uma vez que o objetivo comum é basicamente influenciar hábitos, comportamentos e idéias.

\section{A comunicação como estratégia}

É possível considerar a comunicação corporativa sob o ponto de vista estratégico. Este se constitui, basicamente, no processo de conversão da identidade corporativa - conjunto de instituições simbólicas de uma organização - na imagem corporativa - resultado da percepção da identidade por determinado público. Ao contrário da postura mercadológica da comunicação, que mescla a informação promocional com a persuasão semântica, a comunicação corporativa traduz-se de modo integrado, holístico, englobando os aspectos institucional (valores), comercial (cadeia mercadológica) e administrativo (gestão e processos). De acordo com Matos (2000, p. 67): "Essa junção administrativa permitiria o uso de uma mesma linguagem, adoção de comportamentos comuns e uma maior coerência na política de comunicação da organização."

Em síntese, "a estratégia de comunicação está a serviço da estratégia global da empresa antes de estar a serviço da estratégia de marketing. Seu campo de expressão engloba e sobrepassa o campo de intervenção do marketing" (REGOUBY, 1989, p. 136), daí seu perfil sistêmico.

Um profissional de comunicação corporativa deverá, portanto, assumir a postura de um administrador de conflitos, uma vez que sua responsabilidade não é simplesmente a informação, que implica em unilateralidade, mas a comunicação, em essência um processo de reciprocidade.

Converte-se a prática em comunicação integrada na integração estratégica de diversas ferramentas desenvolvidas de modo planejado: pesquisa, identidade visual, propaganda, merchandising, promoção de vendas, relações públicas e assessoria de imprensa. Isto significa que o exercício da comunicação estratégica é sistematicamente organizado, coordenado, controlado e analisado segundo sua viabilidade.

Além do perfil integrado de comunicação, o perfil dirigido é outra das principais orientações estratégicas da comunicação. Pode-se conceituar a comunicação dirigida como:

Uma forma de comunicação humana destinada a propiciar maior interação entre pessoas e grupos, pois quanto mais direta for, melhor será o resultado de qualquer comunicação. $\mathrm{Na}$ comunicação dirigida, o comunicador e o receptor se identificam. O código empregado é o mais adequado a ambos. O conteúdo é destinado a perdurar no tempo e as mensagens são programadas para atingir toda a audiência. (KUNSCH, 1986, p. 128). 
Sob este ponto de vista, a interação é fruto de um processo detalhado de orientação, focado estrategicamente nos objetivos de comunicação. Caracterizada pela busca de maximização dos resultados e racionalização das despesas, torna-se uma área de resultados efetivos quando é fundamentalmente integrante do processo de gestão da organização. A comunicação dirigida também atua em um amplo sentido que contempla a organização multifacetada, exercendo poder e influência expressiva dentro e fora do seu entorno.

\section{A comunicação como forma de gestão}

$\mathrm{Na}$ medida em que a assimilação dos conceitos de marketing e comunicação torna-se prioritário em prol do fortalecimento institucional do Terceiro Setor, a resistência vai diminuindo e os profissionais deste mercado começam a contextualizar termos e ferramentas de gestão empresarial em suas respectivas áreas de trabalho, o que é considerado um importante passo rumo ao desenvolvimento das organizações sem fins econômicos.

MENEGUETTI (2001, p. 27) descreve nove dimensões da comunicação na realidade da instituição sem fins lucrativos. São elas:

1. Organizacional - baseia-se na criação de espaços e mecanismos para explicar conceitos e procedimentos, divulgados sistematicamente à equipe interna, aos voluntários, aos consultores, à direção, ao conselho, aos fornecedores, de modo a envolvê-los com o processo de gestão da organização;

2. Institucional - tem como objetivo trabalhar a identidade, a formação e a consolidação da imagem da organização, de um programa ou de um determinado projeto;

3. Humanizadora - objetiva a criação de condições para a valorização da participação e da iniciativa individual, considerando o esforço empreendido e estimulando o desenvolvimento de potencialidades;

4. Cultural - a meta é desenvolver uma ação que possibilite integrar pessoas e instituições, tanto da comunidade interna como externa, e criar identifi- cação com sua marca, causa ou bandeira institucional;

5. De captação de recursos - processo para identificar as fontes potenciais doadoras ou financiadoras dos recursos, planejamento, elaboração de propostas, sensibilização, estabelecimento de contatos, negociação e manutenção de relacionamentos;

6. De filiação - busca sensibilizar pessoas ou entidades (empresas, escolas, museus, instituições de ensino e pesquisa, clubes, redes de profissionais) para que se juntem à organização ou ao movimento;

7. De prestação de contas - volta-se para a divulgação de resultados, de forma clara e objetiva, buscando demonstrar impactos sociais quantitativa e qualitativamente, trabalhando com um valor essencial para conferir conhecimento e visibilidade à organização: a transparência;

8. De lobby - trata-se essencialmente do esforço de defender interesses legítimos da organização, para sensibilizar e mobilizar pessoas para uma causa ou ação específica;

9. Política - direciona-se para a criação das condições necessárias para o diálogo com a sociedade e a administração de conflitos.

A autora destaca, ainda, a importância da comunicação dentro do composto de marketing em prol do fortalecimento institucional do Terceiro Setor. Sob este ponto de vista, considera-se que sem a articulação estratégica da comunicação, uma OSC não tem capacidade de desenvolver seu próprio objetivo de mudança social, ou sequer manter-se financeiramente enquanto um empreendimento social.

\section{A comunicação como ferramenta de mobilização social}

Como já citado anteriormente, a existência da OSC se dá pela ausência ou insuficiência do bem estar social em alguma dimensão da sociedade. Tratase, portanto, sob o ponto de vista da comunicação, de um princípio de marketing. Se um nicho de 
mercado não está sendo bem atendido, torna-se uma oportunidade de investimento de negócios a fim de satisfazer aquele mercado e trazer retorno à empresa. Cabe ao profissional de comunicação desenvolver estratégias para mobilização social, utilizando ferramentas de comunicação que levemà mobilização de públicos para as questões que vão ao encontro dos objetivos da organização sem fins lucrativos.

\section{Segmentação de públicos no terceiro setor}

Considerou-se o conceito de público como "aquele a quem se comunica [...] o segmento específico da comunidade com o qual se deseja estabelecer a comunicação, um recorte da sociedade" (MENEGUETTI, 2001, p. 45). Sob este ponto de vista, é necessário chegar ao detalhe, segmentar os públicos o máximo possível, focando o universo mais restrito sobre o qual o trabalho da organização possa ter algum impacto significativo.

Ainda de acordo com a definição da autora a respeito do conceito de segmentação, ou seja, o ato de "...dividir o público da organização em subgrupos constituídos por pessoas que guardam, entre si, interesses e características comuns" (MENEGUETTI, 2001, p. 45), os cinco públicos pesquisados neste trabalho foram divididos em:

- cliente final - o segmento do público que deseja e valoriza o serviço ou produto oferecido pela organização e necessita dele;

- doadores (pessoas físicas e/ou jurídicas) - o segmento do público que repassa recursos para a organização sem necessariamente ter a expectativa de desfrutar benefícios especiais;

- poder público (municipal, estadual e federal) - órgãos governamentais que desenvolvem parcerias com o Terceiro Setor;

- associados (clubes, escolas, universidades, museus, empresas) - o segmento do público que se une à entidade para desfrutar de certos benefícios mútuos;

- mídia - todos os profissionais e veículos de comunicação de massa ou segmentada, potencialmente interessados em informações a respeito do Terceiro Setor.

\section{Um panorama da comunicação no terceiro setor em Guarapuava/PR}

Guarapuava foi descoberta em 1770 pelos portugueses e fundada em 1810. É uma cidade ainda jovem, com cerca de 165 mil habitantes, que uniu povos tão diferentes quanto as tribos indígenas dos Camés, Votorões e Cayeres, até os imigrantes provenientes de diferentes partes da Europa e África. Sua economia encontra-se baseada na agricultura, pecuária e exploração de madeira para exportação. O comércio também se apresenta como grande setor gerador de empregos na região.

$\mathrm{Na}$ Tabela 1, abaixo, estão relacionadas as entidades selecionadas como amostra da pesquisa de campo: 
TABELA 1 - Relação de Entidades Pesquisadoras para levantamento de dados a respeito do panorama da comunicação no Terceiro Setor em Guarapuava/PR - 2004

\begin{tabular}{|c|c|c|c|c|c|}
\hline Entidade & Fundação & Área de atuação & Atendidos & Funcionários & Voluntários \\
\hline $\begin{array}{l}\text { Pastoral da } \\
\text { Criança }\end{array}$ & $27 / 09 / 86$ & saúde e educação & 13.500 & 4 & 1.600 \\
\hline $\begin{array}{l}\text { Lar Escola } \\
\text { Retiro Feliz }\end{array}$ & $10 / 09 / 64$ & educação infantil & 140 & 17 & 30 \\
\hline $\begin{array}{l}\text { Albergue } \\
\text { Frederico Ozanam }\end{array}$ & $20 / 01 / 84$ & $\begin{array}{l}\text { acolhimento e } \\
\text { assistência espiritual }\end{array}$ & $23 /$ dia & 6 & 22 \\
\hline $\begin{array}{l}\text { Associação dos } \\
\text { Pais e Amigos } \\
\text { dos Excepcionais }\end{array}$ & $27 / 08 / 71$ & $\begin{array}{l}\text { saúde e } \\
\text { desenvolvimento } \\
\text { psicomotor }\end{array}$ & 392 & 60 & 4 \\
\hline $\begin{array}{l}\text { Serviço de Obras } \\
\text { Sociais }\end{array}$ & $11 / 10 / 70$ & $\begin{array}{l}\text { assistência para } \\
\text { a terceira idade }\end{array}$ & 50 & 10 & 15 \\
\hline $\begin{array}{l}\text { Associação de } \\
\text { Amigos e } \\
\text { Voluntários } \\
\text { Contra o Câncer }\end{array}$ & $19 / 03 / 01$ & $\begin{array}{l}\text { auxílio aos } \\
\text { portadores } \\
\text { decâncer }\end{array}$ & 40 & 0 & 16 \\
\hline ACOPECC & $18 / 04 / 00$ & $\begin{array}{l}\text { auxílio aos } \\
\text { portadores de câncer }\end{array}$ & 2.000 & 1 & 10 \\
\hline $\begin{array}{l}\text { Ágata Serviços } \\
\text { Sociais }\end{array}$ & $15 / 07 / 02$ & $\begin{array}{l}\text { apoio ao } \\
\text { toxicômano } \\
\text { e drogadito }\end{array}$ & 130 & 6 & 1 \\
\hline $\begin{array}{l}\text { Hospital } \\
\text { Beneficente } \\
\text { São Vicente } \\
\text { de Paulo }\end{array}$ & 1913 & saúde & 20.000 & 228 & 10 \\
\hline $\begin{array}{l}\text { Associação dos } \\
\text { Pais e Amigos } \\
\text { dos Deficientes } \\
\text { Visuais }\end{array}$ & $28 / 03 / 89$ & $\begin{array}{l}\text { apoio ao } \\
\text { deficiente visual }\end{array}$ & 80 & 15 & 25 \\
\hline
\end{tabular}


De forma geral, percebeu-se, por meio da análise dos dados levantados pela pesquisa de campo, que a comunicação das organizações estudadas funciona de maneira informal e restrita as ferramentas básicas de comunicação. A conveniência no uso da comunicação é a característica mais evidente nestas entidades. Os contatos frequentes com os públicos definidos pela pesquisa: cliente final, mídia, poder público, parceiros e mantenedores, não acontece em todas as entidades. A exceção fica por conta dos clientes finais. Entretanto, mesmo nesse caso, ferramentas de comunicação adotadas são incipientes. Nos gráficos a seguir, são apresentados os resultados de forma mais detalhada.

$\mathrm{Na}$ Figura 1 é apresentada uma síntese das ferramentas mais utilizadas de acordo com os segmentos Propaganda, Relações Públicas, Marketing Direto, Eventos e Brindes e em relação a cada um dos públicos considerados na pesquisa. Percebe-se a predominância de palestras e confraternizações, o que evidencia certa preferência pelo contato interpessoal.

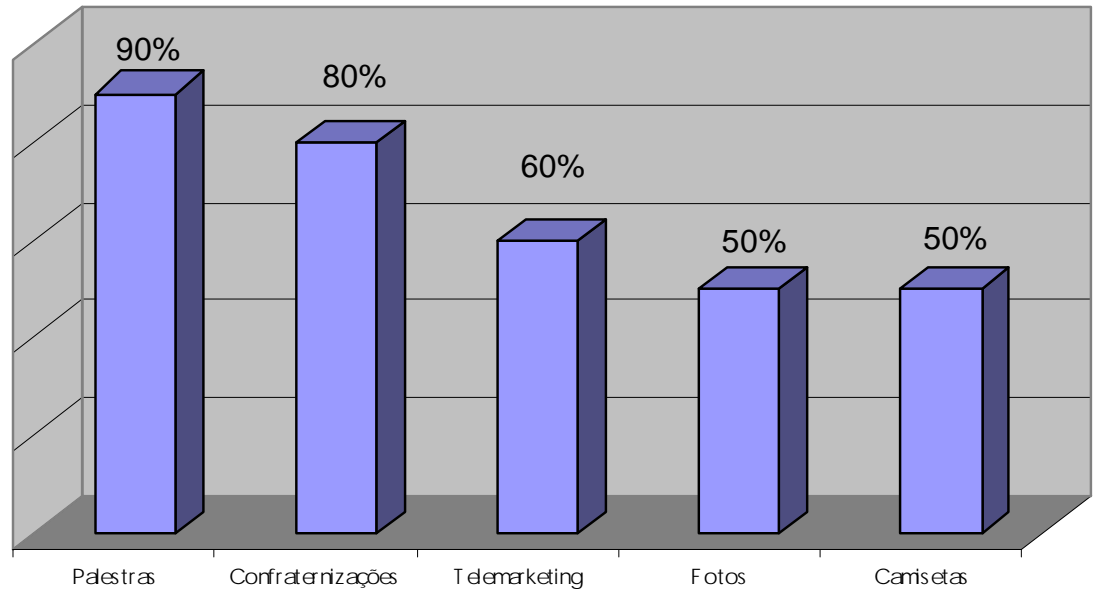

FIGURA 1 - Ferramentas de comunicação mais utilizadas entre as organizações do Terceiro Setor de Guarapuava/PR e seus clientes finais - 2004

A Figura 2 mostra as principais ferramentas de comunicação utilizadas pelas entidades para os contatos com os seus mantenedores. Percebe-se uma melhor distribuição entre as diferentes ferramentas de comunicação, com pre- dominância de cartões de aniversário e natal, palestras, ações de lobby, visitas pessoais e telemarketing, realizados por $30 \%$ das entidades. A seguir estão os jantares e a distribuição de camisas, feitos por $20 \%$ das OSC's.

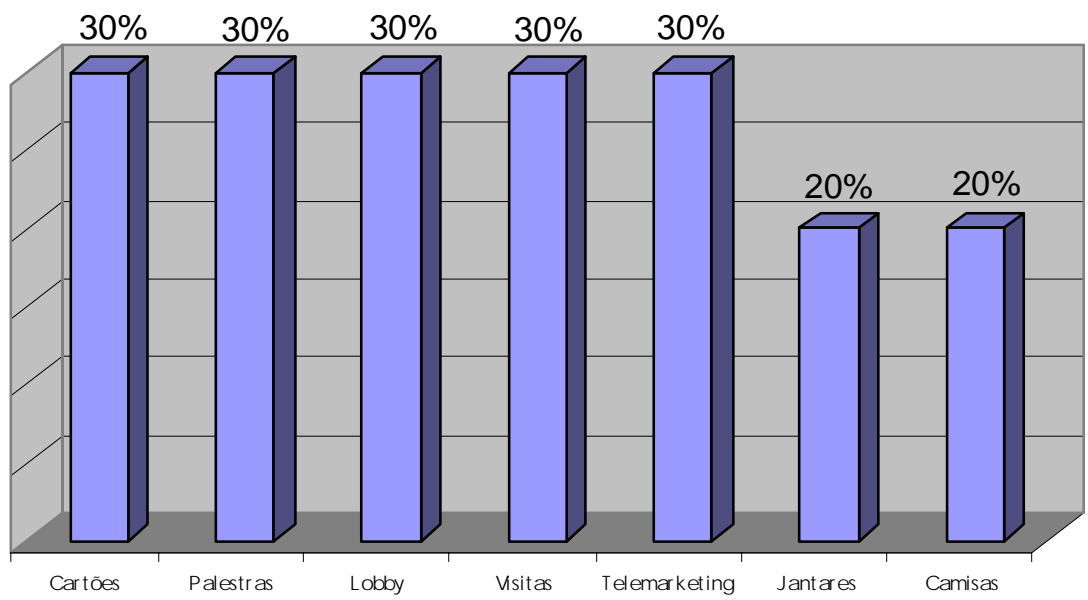

FIGURA 2 - Ferramentas de comunicação mais utilizadas entre as organizações do Terceiro Setor de Guarapuava/ PR e seus Mantenedores - 2004 
Para realizar a comunicação com o Poder Público, a principal ferramenta utilizada, em $70 \%$ dos casos, são os relatórios de prestação de contas anual, o que caracteriza-se mais como uma obrigação do que propriamente uma iniciativa das entidades.
Conforme demonstra a Figura 3, 50\% das organizações mantêm contatos telefônicos e visitam os órgãos governamentais. As brochuras e anúncios impressos são enviados por $20 \%$ e $10 \%$ das organizações realizam reuniões com o Poder Público.

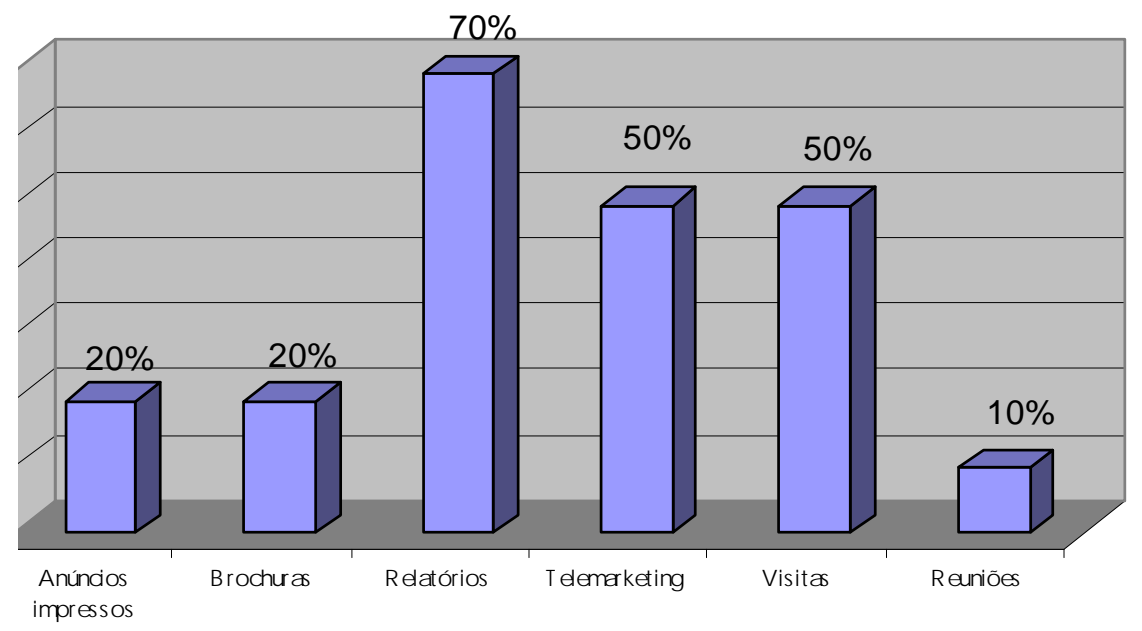

FIGURA 3 - Ferramentas de comunicação mais utilizadas entre as organizações do Terceiro Setor de Guarapuava/PR e o Poder Público - 2004

Os Parceiros, em 70\% dos casos, são informados das atividades ou projetos das entidades por via telefônica. Conforme mostra a Figura 4, as apresenta- ções de vídeos, palestras, ações de lobby, visitas pessoais e almoços acontecem em $30 \%$ das organizações, enquanto outras $20 \%$ distribuem camisas.

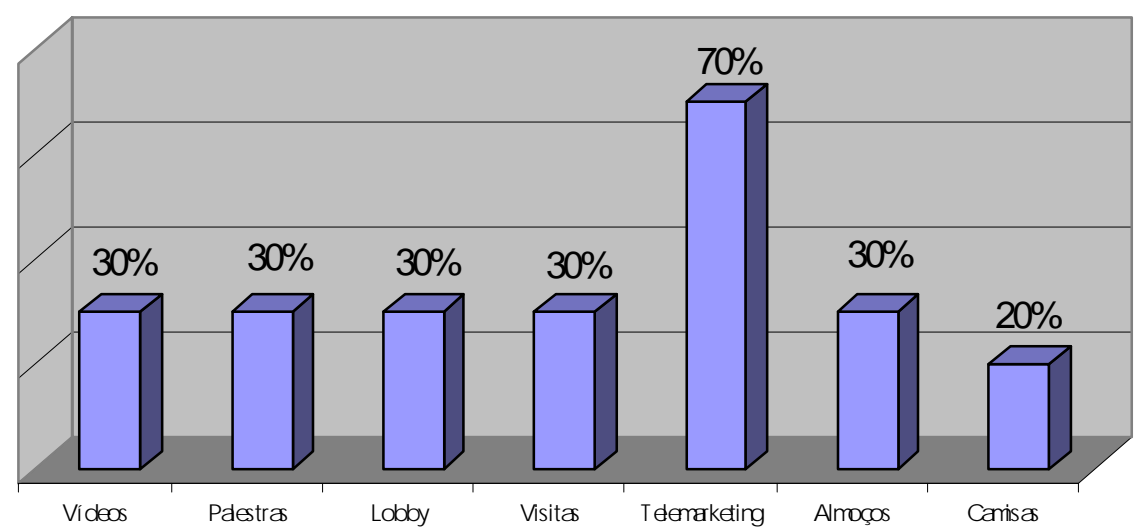

FIGURA 4 - Ferramentas de comunicação mais utilizadas entre as organizações do Terceiro Setor de Guarapuava/PR e os seus Parceiros - 2004 
Para os contatos coma a Mídia, por sua vez, conforme a Figura 5, 70\% das entidades do Terceiro Setor utilizam o telemarketing. As visitas pessoais aos veículos são realizadas por $60 \%$, enquanto outras $10 \%$ realizam jantares, chás e distribuem camisas entre os profissionais da Mídia.

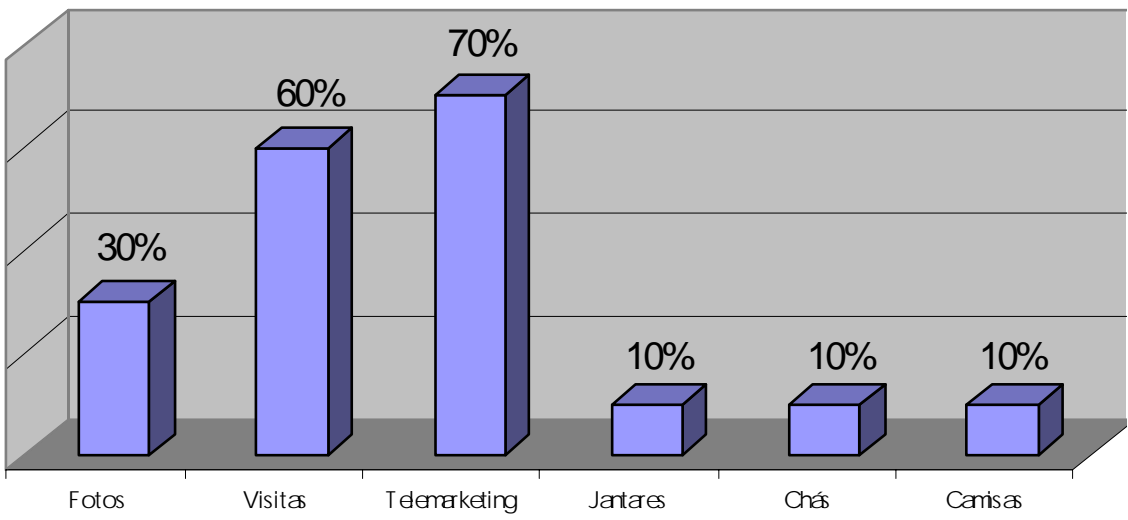

FIGURA 5 - Ferramentas de comunicação mais utilizadas entre as organizações do Terceiro Setor de Guarapuava/PR e a Mídia - 2004

\section{CONSIDERAÇÕES GERAIS}

As ferramentas de comunicação utilizadas pelas entidades variam de acordo com o público a ser atingido. Os clientes finais recebem informações sobre os resultados da entidade por meio de palestras que são realizadas por algumas entidades. Já os Mantenedores quase não recebem informações sobre o que acontece nas entidades para as quais fazem suas doações e, quando isso acontece, em apenas $30 \%$ dos casos, as ferramentas utilizadas são cartões de aniversário e natal, palestras, visitas pessoais e telemarketing.

Com o Poder Público, a principal ferramenta de comunicação são os relatórios anuais de prestação de contas, obrigatórios para as entidades legalmente constituídas e cadastradas em órgãos governamentais. A principal forma de comunicação das entidades com seus Parceiros é o telemarketing, em $70 \%$ dos casos. Sendo os Parceiros associações, clubes, empresas e outras entidades que patrocinam e apóiam as entidades não governamentais, o uso dessa ferramenta como principal contato causa distanciamento e dificuldade de estabelecimento de novas parcerias. Com a Mídia a situação não é muito diferente, em $70 \%$ dos casos pesquisados o contato mais utilizado pelas entidades é realizado por meio do telemarketing, seguido das visitas pessoais em $60 \%$ dos contatos.

Muitas outras ferramentas de comunicação quase não apareceram ou não foram citadas por nenhuma das organizações pesquisadas, entre essas algumas que poderiam trazer grandes diferenciais competitivos para as organizações, tais como: anúncios eletrônicos, cartazes, publicações, revistas da entidade, malas diretas, teatros, adesivos, certificados e projeções audiovisuais. A ausência destas ferramentas no planejamento das entidades pode comprometer seus objetivos de conquista de apoio dos públicos, uma vez que nem sempre se fazem lembrar constantemente como entidades merecedoras da confiança e apoio destes públicos.

Em resumo, de forma geral, as ferramentas mais utilizadas pelas entidades para realizarem suas comunicações com os públicos são as visitas pessoais. O telemarketing vem a seguir como principal ferramenta de comunicação.

Por serem as duas ferramentas que apresentam maior facilidade de operacionalização e economia de custos, as organizações parecem privilegiar esses tipos de contato em detrimento de outras ferramentas que poderiam conferir-lhes maior visibilidade e profissionalismo, principalmente diante dos mantenedores e parceiros, que precisam perceber quais benefícios tangíveis sua contribuição ou apoio estão gerando para os beneficiados das Entidades.

Juntamente com estas duas ferramentas de comunicação, as entidades poderiam utilizar de forma mais profissional os canais da mídia para divulgação de suas atividades e resultados. Desenvolver planejamentos estratégicos de comunicação e captação de recursos e talentos para seus quadros são outras sugestões de estratégias que as entidades poderiam utilizar com mais frequência e senso de oportunidade. 
Dos públicos-alvo pesquisados, aquele que recebe a menor quantidade de informações a respeito das atividades das entidades é justamente o que mais se envolve nas causas e projetos, e que teoricamente apresentam a maior disponibilidade de auxiliá-las em seus projetos, ou seja, os mantenedores.

Diante dos resultados encontrados, uma futura pesquisa, a ser realizada em outras regiões do estado do Paraná, poderá contribuir para comparação de resultados e verificação das ferramentas de comunicação mais utilizadas por entidades em outras partes do estado.

\section{CONSIDERAÇÕES FINAIS}

Verificando-se os resultados da pesquisa, percebe-se que a utilização sistemática de ferramentas de comunicação ainda não é uma prática disseminada entre os vários tipos de organizações do Terceiro Setor em Guarapuava.

Grande parte das organizações pesquisadas não utiliza, sistematicamente, as ferramentas de comunicação integrada, tampouco as possibilidades oferecidas pela comunicação dirigida. As exceções ficam por conta da APAE e da Pastoral da Criança, que já possuem uma estrutura de comunicação desenvolvida e que operam de forma profissionalizada. Todas as outras entidades pesquisadas não tem em seus quadros profissionais de comunicação que poderiam conferir direcionamento e visibilidade adequados aos resultados pretendidos e/ou obtidos pelas entidades.

Como o fortalecimento institucional do Terceiro Setor, previsto na literatura, espera-se que uma comunicação estrategicamente dirigida e integrada em âmbito social seja uma questão de tempo para algumas das organizações pesquisadas.

Considera-se, portanto, que as organizações do Terceiro Setor podem beneficiar-se amplamente do marketing e da comunicação para concretização de seus objetivos organizacionais. $\mathrm{Ou}$ seja, as organizações sem fins econômicos deveriam incorporar estrategicamente a preocupação com a eficiência da relação de troca com seus "mercados".

Para as entidades do Terceiro Setor, a comunicação deve desempenhar um papel estratégico na mobilização e mudança social. Trata- se de contribuir efetivamente nos resultados que a organização busca, significando não apenas uma relação identidade-imagem, mas, sobretudo, uma relação missão-visão.

Concluiu-se que ainda há muito a ser feito para que as entidades pesquisadas alcancem maior profissionalização na utilização das ferramentas comunicação e que percebam a importância que da manutenção do relacionamento contínuo com os seus públicos. Espera-se que, com este e outros trabalhos na área, algumas mudanças de atitude em relação ao planejamento de comunicação comecem a acontecer não apenas no universo das entidades pesquisadas, mas em todas as organizações do Terceiro Setor do país.

\section{REFERÊNCIAS}

BRASIL. Lei n. 9.790, de 23 de março de 1999, $\int 1^{\circ}$. Diário Oficial da União, Brasília, 4 de março de 1999. Disponível em: < http:// www.planalto.gov.br/ccivil_03/LEIS / L9790.htm> Acesso em: 14 ago. 2005.

COELHO, S. de C. Terceiro setor: um estudo comparado entre Brasil e Estados Unidos. São Paulo: SENAC SP, 2000.

GRUNIG, J. (Org.). Excelence in public relations and communication management. New Jersey: Lawrence Erlbaum Associates, 1992.

KUNSCH, M. M. K. Planejamento de relações públicas na comunicação integrada. São Paulo: Summus, 1986.

MATOS, H. Comunicação pública e comunicação global. Revista Líbero, São Paulo, ano 3, v. 3, n. 6, p 64-69, 2000.

MATTELART, A.; MATTELART, M. Histórias das teorias da comunicação. São Paulo: Loyola, 1999.

MENEGUETTI, S. B. Comunicação e marketing: fazendo a diferença no dia-a-dia de organizações da sociedade civil. São Paulo: Global, 2001.

MORAN, J. M. Mudanças na comunicação pessoal. São Paulo: Paulinas, 1998. 
REDE DE INFORMAÇÕES DO TERCEIRO SETOR - RITS. Seção informações. 2004. Disponível em: <http://www.rits.org.br>. Acesso em: 24 maio 2004.

REGO, F. G. T. do. Comunicação empresarial comunicação institucional. São Paulo: Summus, 1986.

REGOUBY, C. La comunicación global. Barcelona: Gestió, 1989.

Recebido: 13/05/2008

Received: 05/13/2008

Aprovado: 29/05/2008

Approved: 05/29/2008 